\title{
EFFICIENCY EVALUATION OF PIRFENIDONE IN EGYPTIAN IDIOPATHIC PULMONARY FIBROSIS PATIENTS
}

\author{
Ramadan M Nafee,Waheed M Shoman, Mohammed M N AboZaid and Dalia Abd El \\ Wahed \\ Chest Diseases Department*, Faculty of Medicine, Zagazig University
}

Received: 8 October 2018

Accepted: 22 December 2018

Corresponding author

Dalia Abd Elwahed Ibrahim, baligh050@gmail.com.

\begin{abstract}
Background:. Idiopathic pulmonary fibrosis (IPF) is a complicated disease in which histopathological abnormalities in the form of, proliferation of mesenchymal cell, fibrosis, overproduction and disorganization of collagen deposition, extra cellular matrix changes with distortion of pulmonary structure and the appearance of subpleural cysts, with accumulation of both myofibroblast and fibroblast. Pirfenidone has been available in Japan since 2008.In 2011, the approval by the European Medicine Agency (EMA) was indicated by the efficacy of pirfenidone in decreasing lung function deterioration in IPF patients.
\end{abstract}

Aim of the Study: The aim of the study is to study the efficiency and safety of Pirfenidone in a group of IPF Patients.

Ethical aspects: The thesis protocol was approved by IRB committee, Faculty of Medicine, Zagazig University.

Subjects and Methods: This study was carried on 40 adult patients with IPF. Patients were divided into:

- Group (A): 20 patients accepted to be treated with pirfenidone.

- Group (B): also 20 patients they have been treated with conventional treatment for IPF

Results: Mean change in distance walked during 6MWD test was $0.05 \pm 56.24$ for group (A) and $-12.65 \pm 67.86$ for group (B). Mean decline in predicted FVC was $-0.89 \% \pm 14.55$ for group (A) and $-5.48 \% \pm 10.89$ for $\operatorname{group}(\mathrm{B})$ there were progression of the disease according to HRCT in $60 \%$ in $\operatorname{group}(\mathrm{A})$ and $70 \%$ in group(B), while only $10 \%$ in group (A) showed regression of the disease with statistical significant differences between two groups.

Conclusion: Pirfenidone didn't improve health related quality of life in IPF patients, Pirfenidone did not affect oxygenation in treatment group after 3 months therapy, Pirfenidone has good impact on radiological presentation of IPF patients. Pirfenidone not only slow loss in FVC but also improved it in one third of treated patients, GIT upset is the main adverse effects of pirfendone which are mild.

Key words:Idiopathic pulmonary fibrosis,Perfinidone,steroids

\section{INTRODUCTION}

diopathic pulmonary fibrosis (IPF) is nonpredictable, irreversible, debilitating and finally it is a fatal chronic fibrotic lung disease associated with dyspnea and a progressive reduction in lung function. From all forms of idiopathic interstitial pneumonias, idiopathic pulmonary fibrosis is considered the most frequent and fatal form , although the clinical course varies, prognosis is poor with a median survival from the onset of symptoms of only 2.8-4.2 years (1).

Early, IPF was considered to be an inflammation-driven disorder so initial treatment aimed to defeat and suppress the inflammatory process (e.g. corticosteroids and immunomodulatory agents) ,However, there is a new clue that inflammation is not a major histopathological finding in UIP and that fibroblast foci develop early in UIP (2) 
Nafee et al

Pirfenidone was the first approved antifibrotic agent for the treatment of IPF. It was approved in 2008 and gave the hope for IPF patients and physicians for a new era in the treatment of IPF (3), The pirfenidone antifibrotic effect caused suppression of inflammatory cytokines, as indicated in a mouse model of bleomycin-induced pulmonary fibrosis .Pirfenidone inhibits transforming growth factor-b (TGF-b) and has antifibrotic, anti-inflammatory, and antioxidant effects (4).

\section{- Technical design:}

- Site of the study:

This study was carried out at Chest Department, Zagazig University Hospitals across one year period starting from January 2017.

\section{- Patients:}

This study was conducted on 40 IPF patients, randomly selected from the Chest Outpatients Clinic attendants according to the inclusion criteria. All patients were clinico-radiologically diagnosed as IPF prior to inclusion in the study.

Patients were divided into:

- Group (A): This group included twenty patients who accepted to start pirfenidone treatment according to the advice of their prescribing physicians. They were 13 females and 7 males. Their age was $57.1 \pm 8.19$ years.

- Group (B): This group included 20 sex (13 females and 7 males) and age (57.25 \pm 8.05 years) matched patients starting conventional treatment for IPF (systemic steroids and azathioprine) according to their prescribing physicians.

\section{Inclusion Criteria:}

- Patients who fulfilled investigations according the study protocol.

- Patients who kept on follow up for the entire study.

- All patients fulfilling the clinical and radiological criteria of IPF. According the IPF guidelines of the American Thoracic Society/European Respiratory
Zagazig University Medical Journals

Society /JRS/ Latin-American Thoracic Association (ALAT). (5).

- Clinically stable IPF patients.

- Patients who signed informed consent.

\section{Exclusion criteria:}

- Clinical and radiological features of idiopathic interstitial pneumonias other than IPF.

- IPF patients with neuromuscular disease, chronic renal failure, $\mathrm{HCV}$ infection, evidence of coexisting respiratory infection, lung cancer and other concomitant pulmonary diseases.

- History of pirfenidone therapy to avoid pervious effect of pirfenidone.

\section{Study design}

Controlled Clinical Study

(Interventional Drug Study)

- Methods:

The following parameters were fulfilled for all the patients

1-Medical history and clinical examination; 2- Complete clinical examination: Full clinical examination has been done.

3- Laboratory investigations (before and at end of treatment or, moreover, if recommended):

4- Arterial blood gases analysis (ABGs).

5- Spirometric Pulmonary Function Testing (PFT)

6- Plain chest X-ray (postero-anterior and lateral views).

\section{7- HRCT of Chest}

HRCT of Chest was performed to all patients in this study, before and after recruitment. Findings of HRCT are fundamental in the diagnosis of IPF, Diagnosis of IPF is possible without surgical lung biopsy when HRCT demonstrates a typical IPF pattern and causes of interstitial pneumonia remain unknown. treatment (Group B) was evaluated for three months

\section{Treatment}

In this study the effectiveness of pirfenidone therapy (Group A) vs. conventional period. Follow up the studied cases was carried out through; symptoms score, HRCT of the chest, arterial blood gases, 6 minutes' walk test 
and spirometric pulmonary function test pre- and post- recruitment. Possible treatment side effects were monitored

\section{DOSAGE AND ADMINISTRATION}

Testing prior to pirfenidone
Administration

Conduct liver function tests prior to initiating treatment with pirfenidone

Recommended Dosage The recommended daily maintenance dosage of pirfenidone is $801 \mathrm{mg}$ (three $267 \mathrm{mg}$ tablets) three times a day with food for a total of $2403 \mathrm{mg} / \mathrm{day}$. Doses should be taken at the same time each day.

Dosage Titration for pirfenidone in Patients with IPF (6).

Pirfenidone therapy is started with a 14-day titration regimen of $801 \mathrm{mg} /$ day (one capsule, three times per day) on days 1-7 of 1,602 $\mathrm{mg}$ /day (two capsules, three times per day) on days 8-14. The daily dose from day 15 onwards is pirfenidone $2,403 \mathrm{mg} /$ day (three capsules, three times per day)

\section{STATISTICAL ANALYSES}

All statistical analyses were carried out using the SPSS (statistical package for the social science software) statistical package version 20.0 (SPSS Inc., Chicago, IL, USA) for Windows. Quantitative data were expressed as mean and standard deviation $(\mathrm{X}+\mathrm{SD})$ and analyzed by applying student t-test for comparison of two groups of normally distributed variables. The results of the " $t$ "value is then checked on student's " $t$ "-table to find out the significance level ( $p$-value) according to the degree of freedom.

\section{RESULTS}

Table 1 Socio-demographic data of studied patients

\begin{tabular}{|c|c|c|c|c|c|c|c|}
\hline & \multicolumn{2}{|l|}{ Group } & \multirow[t]{2}{*}{ Total } & \multirow[t]{2}{*}{$\mathbf{X}^{2}$} & \multirow[t]{2}{*}{$\mathbf{P}$} \\
\hline & & & Group A & Group B & & & \\
\hline \multirow[t]{10}{*}{ Sex } & \multirow[t]{2}{*}{$\mathbf{F}$} & $\mathbf{N}$ & 13 & 13 & 26 & \multirow[t]{10}{*}{0.00} & \multirow[t]{10}{*}{1.00} \\
\hline & & $\%$ & $65.0 \%$ & $65.0 \%$ & $65.0 \%$ & & \\
\hline & \multirow[t]{2}{*}{$\mathbf{M}$} & $\mathbf{N}$ & 7 & 7 & 14 & & \\
\hline & & $\%$ & $35.0 \%$ & $35.0 \%$ & $35.0 \%$ & & \\
\hline & \multirow[t]{2}{*}{ EX Smoker } & $\mathbf{N}$ & 4 & 6 & 10 & & \\
\hline & & $\%$ & $20.0 \%$ & $30.0 \%$ & $25.0 \%$ & & \\
\hline & \multirow[t]{2}{*}{ Non Smoker } & $\mathbf{N}$ & 10 & 5 & 15 & & \\
\hline & & $\%$ & $\mathbf{5 0 . 0 \%}$ & $25.0 \%$ & $37.5 \%$ & & \\
\hline & \multirow{2}{*}{\begin{tabular}{|l|} 
passive \\
smoker
\end{tabular}} & $\mathbf{N}$ & 1 & 5 & 6 & & \\
\hline & & $\%$ & $5.0 \%$ & $25.0 \%$ & $15.0 \%$ & & \\
\hline \multirow[t]{4}{*}{ Comorbidities } & \multirow[t]{2}{*}{ DM } & $\mathbf{N}$ & 3 & 7 & 10 & \multirow{4}{*}{$\begin{array}{l}8.2 \\
4.09\end{array}$} & \multirow{4}{*}{\begin{tabular}{|l}
$\mathbf{0 . 0 0 4} *$ \\
$0.043 *$
\end{tabular}} \\
\hline & & $\%$ & $15 \%$ & $35 \%$ & $25 \%$ & & \\
\hline & \multirow[t]{2}{*}{ HTN } & $\mathbf{N}$ & 4 & 7 & 11 & & \\
\hline & & $\%$ & $20 \%$ & 35 & $27.5 \%$ & & \\
\hline \multirow{2}{*}{\multicolumn{2}{|c|}{ Total }} & $\mathbf{N}$ & 20 & 20 & 40 & & \\
\hline & & $\%$ & $100.0 \%$ & $100.0 \%$ & $100.0 \%$ & & \\
\hline
\end{tabular}

This table shows Socio-demographic data of both patients' groups Most of patients were females (26 patients) with percentage of 65\%, 13 in group (A) and 13 in group (B), none of the patients was current smoker , 15 patients were nonsmokers with percentage of $37.5 \%, 10$ in group (A) and 5 in group (B), 10 patients were Ex-smokers with percentage of 25\%, 4 in group (A) and 6 in group (B), 10 patients had DM with percentage of $25 \%, 3$ in group (A) and 7 in group (B), while 11 patients had hypertension with percentage of $27.5 \%, 3$ in group (A) and 7 in group (B), no statistical significant differences regarding sex, special habits and $(\mathrm{P}>0.05)$ but there was significant statistical difference between patients' groups according to comorbidities $(\mathrm{P}<0.05)$. 
Table 2 Six minutes walk test and Oxygen saturation before and after treatment in both groups.

\begin{tabular}{|c|c|c|c|c|c|c|c|}
\hline & & Group & $\mathrm{N}$ & Mean & Std. Deviation & $\begin{array}{l}\text { t/ Mann } \\
\text { Whitney }\end{array}$ & $\mathrm{P}$ \\
\hline \multirow{6}{*}{ 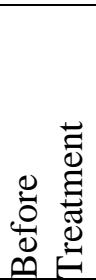 } & \multirow[t]{2}{*}{ Distance } & Group A & 20 & 318.15 & 50.92851 & \multirow[t]{2}{*}{.927} & \multirow[t]{2}{*}{.360} \\
\hline & & Group B & 20 & 301.90 & 59.62153 & & \\
\hline & \multirow{2}{*}{$\begin{array}{l}\text { O2_saturation pre } \\
\text { test }\end{array}$} & Group A & 20 & 93.95 & 1.90498 & \multirow[t]{2}{*}{1.76} & \multirow[t]{2}{*}{0.086} \\
\hline & & Group B & 20 & 92.85 & 2.03328 & & \\
\hline & \multirow{2}{*}{$\begin{array}{l}\text { O2_saturation } \\
\text { post test }\end{array}$} & Group A & 20 & 88.35 & 3.73145 & \multirow[t]{2}{*}{0.41} & \multirow[t]{2}{*}{0.68} \\
\hline & & Group B & 20 & 87.80 & 4.65211 & & \\
\hline \multirow{4}{*}{ 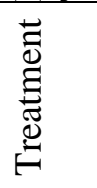 } & \multirow[t]{2}{*}{ Distance } & Group A & 20 & 318.20 & 56.24346 & \multirow[t]{2}{*}{1.469} & \multirow[t]{2}{*}{.150} \\
\hline & & Group B & 20 & 289.25 & 67.86509 & & \\
\hline & \multirow{2}{*}{$\begin{array}{l}\text { O2_saturation pre } \\
\text { test }\end{array}$} & Group A & 20 & 93.45 & 2.35025 & \multirow[t]{2}{*}{1.980} & \multirow[t]{2}{*}{0.055} \\
\hline & & Group B & 20 & 91.55 & 3.59056 & & \\
\hline \multirow{2}{*}{ 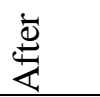 } & \multirow{2}{*}{$\begin{array}{l}\text { O2_saturation } \\
\text { post test }\end{array}$} & Group A & 20 & 87.40 & 5.35478 & \multirow[t]{2}{*}{1.702} & \multirow[t]{2}{*}{0.097} \\
\hline & & Group B & 20 & 84.15 & 6.65128 & & \\
\hline
\end{tabular}

This table shows that there is no change in distance of the six minutes walk test in pirfenidone group after treatment but there is loss in distance of the six minutes walk test in other group after treatment with no statistical significant differences between two groups $(\mathrm{P}>0.05)$.

For Oxygen saturation the table shows loss in both groups after treatment but the loss in pirfenidone group was less than other group with no statistical significant differences between two groups $(\mathrm{P}>0.05)$

Table 3 Dyspnea severity before and after treatment among studied groups

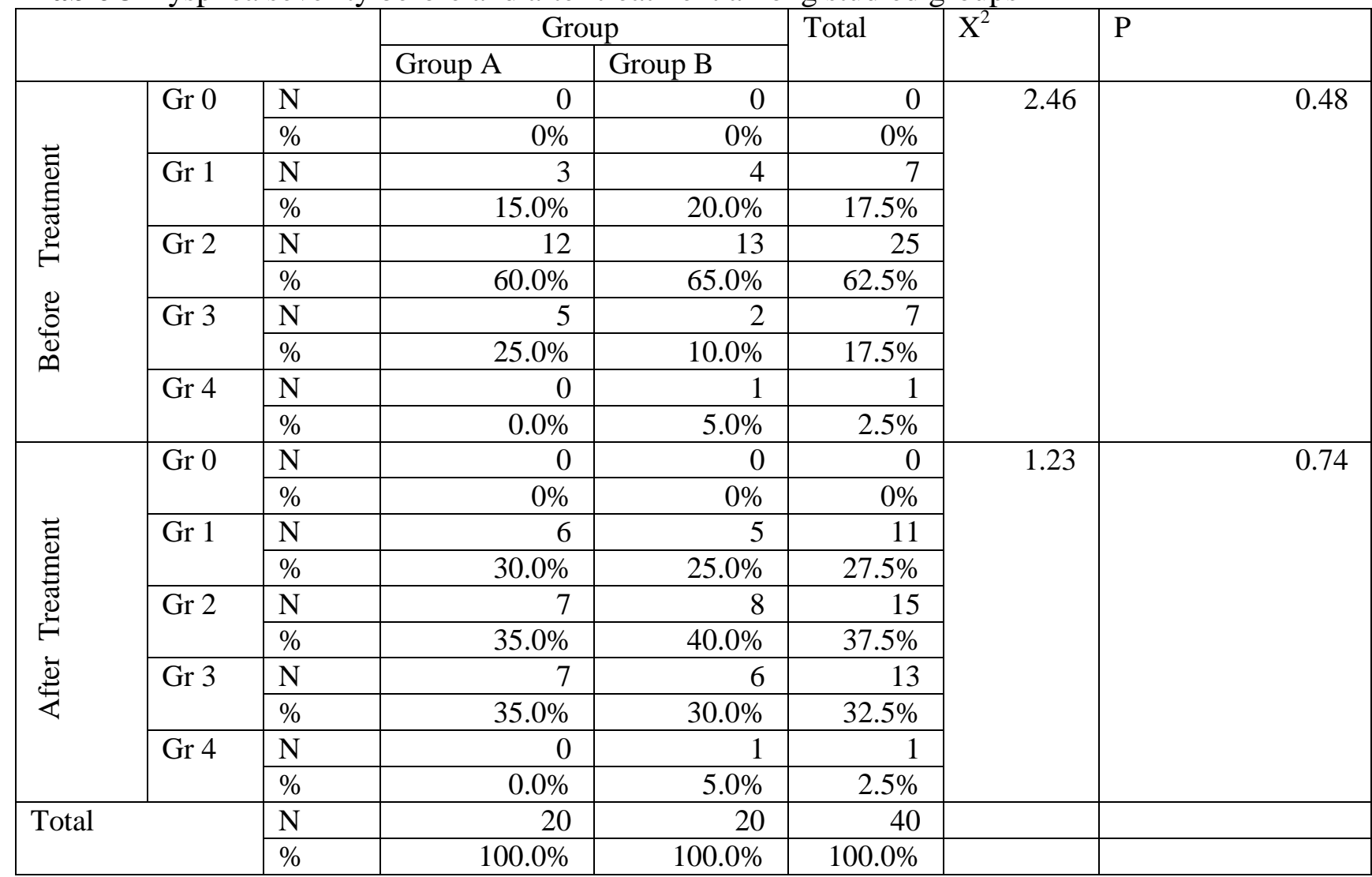

This table show grades of Dyspnea according to mMRC before and after treatment among studied groups with no statistical significant differences between two groups neither before nor after treatment $(\mathrm{P}>0.05)$. 
Table 4 Changes of distance in 6 min walk test before and after treatment in Group (A)

\begin{tabular}{|l|l|l|l|l|l|}
\hline & Mean & N & $\begin{array}{l}\text { Std. } \\
\text { Deviation }\end{array}$ & Paired t & P \\
\cline { 1 - 4 } $\begin{array}{l}\text { Distance before } \\
\text { treatment }\end{array}$ & $\mathbf{3 1 8 . 1 5}$ & $\mathbf{2 0}$ & $\mathbf{5 0 . 9 2 8 5 1}$ & $\mathbf{- . 0 1 7 -}$ & $\mathbf{. 9 8 6}$ \\
\cline { 1 - 4 } $\begin{array}{l}\text { Distance after } \\
\text { treatment }\end{array}$ & $\mathbf{3 1 8 . 2 0}$ & $\mathbf{2 0}$ & $\mathbf{5 6 . 2 4 3 4 6}$ & & \\
\hline
\end{tabular}

This table shows mean Distance in 6 Min Walk test before and after treatment $318.15 \pm 50.92$, $318.2 \pm 56.24$ respectively in group (A) the distance is almost the same before and after treatment with no statistical significant improvement $(\mathrm{P}>0.05)$.

Table 5 Weight of studied patients before and after treatment in $\mathrm{Kgs}$

\begin{tabular}{|c|c|c|c|c|c|c|}
\hline (2) & Group & $\mathbf{N}$ & Mean & $\begin{array}{l}\text { Std. } \\
\text { Deviation }\end{array}$ & $\mathbf{t}$ & $\mathbf{P}$ \\
\hline \multirow{2}{*}{$\begin{array}{l}\text { Before } \\
\text { treatment }\end{array}$} & Group A & 20 & 88.20 & 15.83667 & \multirow[t]{2}{*}{.837} & \multirow[t]{2}{*}{.408} \\
\hline & Group B & 20 & 84.25 & 13.96565 & & \\
\hline \multirow{2}{*}{$\begin{array}{l}\text { After } \\
\text { treatment }\end{array}$} & Group A & 20 & 85.95 & 15.62884 & \multirow[t]{2}{*}{$-.450-$} & \multirow[t]{2}{*}{.655} \\
\hline & Group B & 20 & 88.10 & 14.57431 & & \\
\hline
\end{tabular}

This table shows the mean weight of two groups before and after which found $88.2 \pm 15.83 \mathrm{KG}$ for group (A) and $84.25 \pm 13.96$ for group (B) before treatment and $85.95 \pm 15.62 \mathrm{KG}$ for group (A) and $88.1 \pm 14.57$ for group (B) after treatment there is a weight gain in patients of group (B) and weight loss in patients of group (A) with no statistical significant differences between two groups after treatment $(\mathrm{P}>0.05)$.

\section{DISCUSSION}

Idiopathic pulmonary fibrosis (IPF) is a specific form of fibrosed interstitial pneumonia which is progressive, chronic and its cause isn't known. It is limited to the lungs, occurs mainly in older adults and is associated with histological and/or radiological characteristics of usual interstitial pneumonia (UIP) (7)

Although the disease has been considered rare, it occurs with same rate of stomach, brain, and testicular cancers $(\mathbf{8})$.

After the explanation of the nature of the disease that appears to be related to inflammation and fibrosis, this gives us the idea to begin the "anti-fibrotic" era (9).

These are in agreement with Suraj et al., (2015) (10). In this Indian study of 23 IPF patients who were followed up for one year, female patients were $54 \%$. Patients had DM $(12.5 \%)$ and hypertension (12.5\%). Salih et al., (2016) (11) reported that none of their IPF patients were current smokers.
In contrary, King et al., (2014) (12) reported that most of their patients were males with percentage of $79.9 \%$ for pirfenidone group and 76.9 for placebo group. Albera et al., (2016) (13) reported that Ex-smokers were percentage of $64.4 \%$. Tzouvelekis et al., (2017) (14) reported that current smokers at the time of their study constituted $21.3 \%$

The minimum clinically important difference in 6 minutes' walk distance test (6MWDT) distance in patients with idiopathic pulmonary fibrosis has been reported as 24-45 meter. (15).

This was in accordance with Noble et al., (2011) (16) who found no significant differences in mean change in distance walked during 6MWD test $(\mathrm{P}>0.05)$ which was $-45.1 \% \pm 32$ in patients received pirfenidone and

$-76.9 \% \pm 60.4$ in patients of placebo group, respectively in CAPACITY 006. When comparing the distance lost on follow up in current study and their study, their patients lost more distance. This obviously attributed to the fact their study duration was 72 weeks 
while in current study it was about 12 weeks only.

In contrary King et al., (2014) (12) and Albera et al., (2016) (13) found that patients who received pirfenidone had significant differences in mean change in distance walked during 6MWD test compared with placebo. While Hosein et al., (2016) (17) found slight improvement in 6MWD test distance in patients who received pirfenidone. This is in agreement with Noble et al., (2011) (16) and King et al., (2014) (12) who found that no significant difference was noted in worst $\mathrm{SpO}_{2}$ during 6MWD test between both pirfenidone and placebo groups.

A compelling support to these results was given by Noble et al., (2011) (16) and King et al., (2014) (12) who found no significant difference in dyspnea between pirfenidone and control groups.

This result is contraindicated by Albera et al., (2016) (13) who found significant difference between the pirfenidone and placebo groups in dyspnea $(\mathrm{P}<0.05)$. This may be attributed to the longer duration of their study; 12 months compared to 3 months in the current study

These results are matching Harari et al., (2015) (18) who found no statistical significant improvement in distance walked during 6MWD test.

On the other hand; the results of this study were in contrast with the results of Suraj et al., (2015) (10) who found significant improvement in distance walked during 6MWD test in pifenidone group.

The explanation of previous results was that the sample size of current study was small compared to the other, the duration of current study was only 3 months and patient were proved only according to definite pattern of UIP on HRCT.

The main side effect of steroids is increasing of weight

Weight loss is a side effect of pirfenidone. This was reported in previous studies Noble et al., (2011) (16) (8\%), King et al., (2014) (12) (12.6\%) and Salih et al., (2016) (11) (23\%))

\section{REFERENCES}

1-Israël-Biet D, Juvin K, Dang Tran K, et al (2014): Idiopathic pulmonary fibrosis: diagnosis and treatment in 2013. Rev PneumolClin; 70: 108-117. French

2-Sandbo N (2014): Mechanisms of fibrosis in IPF. In: Meyer KC, Nathan SD, editors. Idiopathic pulmonary fibrosis: a comprehensive clinical guide. New York: Humana Press; p. 161-205.

3-Takeda $Y$, Tsujino $\mathbf{K}$, Kijima $T$, et al (2014): Efficacy and safety of pirfenidone for idiopathic pulmonary fibrosis.Patient Preference and Adherence; 8 361-370.

4-Sakamoto S, Muramatsu Y, Satoh K et al (2015): Effectiveness of combined therapy with pirfenidone and inhaled $\mathrm{N}$ - acetylcysteine for advanced idiopathic pulmonary fibrosis: a casecontrol study. Respirology; 20: 445-52.

5- Raghu G, Collard HR, Egan JJ, et al (2011): An official ATS/ERS/JRS/ALAT statement: idiopathic pulmonary fibrosis: evidencebased guidelines for diagnosis and management. Am J Respir Crit Care Med; 183:788-824.

6-European Medicines Agency (2014): Esbriet (pirfenidone) hard capsules: EU summary of product characteristics. http://www.ema. europa.eu. Accessed 5 Jan 2015

7-Nakamura $H$ and Aoshiba $K$ (2016): Idiopathic Pulmonary Fibrosis Advances in Diagnostic Tools and Disease Management. Springer Japan; 978-4-431-55582-7.

8-Hutchinson J, Fogarty A, Hubbard R, et al (2015): Global incidence and mortality of idiopathic pulmonary fibrosis: a systematic review. Eur Resp J; 46: 795-806

9-Bando M, Yamauchi H, Ogura $T$, et al(2016): Clinical Experience of the Longterm Use of Pirfenidone for Idiopathic Pulmonary Fibrosi .Intern Med ; 55: 443-448, 2016

10-Suraj KP, KumarN K, Jyothi $E$, et al (2016): Role of Pirfenidone in Idiopathic Pulmonary Fibrosis - A Longitudinal Cohort Study. Journal of The Association of Physicians of India; 64(5) :36-41

11-Salih G N, Shaker S B, Madsen HD, et al (2016): Pirfenidone treatment in idiopathic pulmonary fibrosis: nationwide Danish results .European Clinical Respiratory Journal 3: 3260

12-King Jr TE, Bradford WZ, CastroBernardini S, et al (2014): Aphase 3 trial of pirfenidone in patients with idiopathic pulmonary fibrosis. N Engl J Med; 370:208392

13-Albera C, Costabel U, Fagan $E$ A, et al (2016): Efficacy of pirfenidone in patients with idiopathic pulmonary fibrosis with more 
Nafee et al

preserved lung function. Eur Respir J; 48: 843-851

14-Tzouvelekis1 A, Karampitsakos T, Ntolios P , et al (2017) :"Real- World" Outcomes of Pirfenidone in Idiopathic Pulmonary Fibrosis in Greece.Front. Med; 4:213.

15-Du Bois RM, Albera C, Bradford WZ, et al (2010): 6-minute walk test distance (6MWD) is a reliable, valid, and responsive outcome measure that predicts mortality in patients with IPF. Am J Respir Crit Care Med; 1;183(9):1231-7.

16-Noble PW, Albera C, Bradford WZ, et al (2011): Pirfenidone in patients with

\section{Zagazig University Medical Journals}

idiopathic pulmonary fibrosis (CAPACITY): two randomised trials. Lancet; 377(9779):1760-9.

17-Hosein $K$, Le $J$ and Mura M(2017): Assessing the Therapeutic Response to Pirfenidone in Idiopathic Pulmonary Fibrosis: Can We Do Better than with Forced Vital Capacity Alone?. Lung 195:101-105

18-Harari S, Caminati A, Albera $\mathrm{C}$, et al (2015): Efficacy of pirfenidone for idiopathic pulmonary fibrosis: An Italian real life study. Respir Med109

How to cite this article: Nafee RM, Shoman WM, AboZaid MMN, Abd El Wahed D. Efficiency evaluation of pirfenidone in Egyptian idiopathic pulmonary fibroisis patients. ZUMJ 2019; 25 (1): 85-91. 